\title{
Micronuclei induced in erythrocytes of Cyprinus carpio (teleostei, pisces) by X-rays and colchicine
}

\author{
B. Gustavino*, K.A. Scornajenghi, S. Minissi, E. Ciccotti \\ Dipartimento di Biologia, Università di Roma 2, TorVergata, Via della Ricerca Scientifica, 00133 Rome, Italy \\ Received 23 January 2001; received in revised form 17 April 2001; accepted 25 April 2001
}

\begin{abstract}
In the present work the induction of micronuclei in erythrocytes of Cyprinus carpio treated with X-rays and colchicine is studied for the evaluation of mutagenic effects of both clastogenic and mitoclastic (spindle poisoning) agents in this system.

Three different experiments were performed treating groups of laboratory-reproduced animals with (1) single doses of $\mathrm{X}$-rays $(0.1,0.5$ and $2 \mathrm{~Gy})$; (2) a single i.p. injection of colchicine at the concentrations: $1.6 \times 10^{-2}, 8 \times 10^{-2}, 0.4 \mathrm{and} 2 \mathrm{mg} / \mathrm{kg}$ b.w. so as to mimic an acute exposure to the agent and (3) six repeated i.p. injections of the first three concentrations of colchicine, over a period of 18 days, so as to mimic a chronic exposure. Repeated blood samplings were performed by cardiac puncture over a period of about 2 months after the treatment and micronucleus frequencies were determined at multiple times on the same individuals after mutagen exposure. A dose-dependent increase in the micronucleus frequency was observed in irradiated fish and a peak value detected at 21 days. Slight increases of micronucleus frequencies were also observed in both colchicine experiments only for the highest concentrations at the earliest sampling time. Higher concentrations of colchicine clearly showed a lethal effect. According to the present data the micronucleus frequency induced by the highest colchicine dose is comparable to that observed after $0.1 \mathrm{~Gy}$ of X-ray irradiation. (c) 2001 Elsevier Science B.V. All rights reserved.
\end{abstract}

Keywords: Fish; Erythrocytes; Micronuclei; X-rays; Colchicine

\section{Introduction}

Teleost fish are becoming organisms of choice in the field of environmental mutagenesis both because it has been demonstrated that fish are sensitive also to low concentrations of genotoxicants such as in polluted environments and because they are particularly suitable organisms as bioindicators, due to their role in the biotic communities [1,2].

Mutagenic damage in fish can be evaluated using a variety of genetic end-points. Among the cytogenetic

\footnotetext{
${ }^{*}$ Corresponding author. Tel.: +39-6-72594812; fax: +39-6-2023500.

E-mail address: gustavino@bio.uniroma2.it (B. Gustavino).
}

assays, the micronucleus ( $\mathrm{MN}$ ) test in fish erythrocytes has been shown to be simple, reliable and sensitive (see [3] for a review). Furthermore, it has been successfully applied for the in situ detection of mutagenicity in polluted environment. A significant increase in MN frequency in erythrocytes of fish collected in polluted marine or fresh water environments, compared to fish collected in reference sites was in fact observed by different authors [4-8].

Nevertheless, in the framework of validation of this test system for its employment in environmental monitoring of fresh and sea water quality, a better understanding of the real sensitivity and reliability of teleost fish is needed. Efforts in this direction have been made: the mutagenic damage was induced under laboratory 
conditions by treatments with chemical and physical clastogens and then measured in different target tissues, such as erythrocytes, gills, fins and liver [9-13]. In the generally followed protocol, group of fish were treated by injection or water exposure, with different doses of known mutagens, then killed at one or several sampling times and tested for MN induction.

The present work was thought to assist in the assessment of the model: MN induction was investigated in erythrocytes of laboratory-reproduced carps treated with two reference mutagenic agents: X-rays as a direct clastogen and colchicine for the mitoclastic effect, i.e. mitotic spindle damage. Several sampling times were planned, covering a period of about 2 months, in order to study the time course of MN induction in blood erythrocytes. This rationale was planned so as to be able to directly compare the environmentally induced mutagenic damage to experimentally designed positive controls, covering both mutagenic damage inducers.

While clastogenic effects induced by X-rays, namely the time course of $\mathrm{MN}$ induction, have been investigated in erythrocytes of rainbow trout [12], similar investigations in fish erythrocytes on $\mathrm{MN}$ induction by spindle poisons have never been carried out; actually, the effect of colchicine has been tested for $\mathrm{MN}$ induction in cephalic kidney erythrocytes at $24 \mathrm{~h}$ post-treatment [14], or employed to the induce c-mitotic arrest for chromosome analysis [10,15-18]. Since MN analysis represents a cytogenetic end-point which can detect mutagenic effects due to both chromosome breakage and loss, there it is important to study the sensitivity of the fish erythrocyte system to both clastogenic and spindle poisoning agents for $\mathrm{MN}$ induction.

Colchicine induces different levels of damage to the mitotic apparatus: from c-mitosis, to disrupted or multipolar mitoses, to single chromosome loss. Mitotic arrest (c-mitosis) is induced by the highest doses. At lower doses a decreasing proportion of c-mitoses and an increasing one of chromosome/chromatid losses can be observed, while the frequency of all mitotic anomalies decreases. At the lowest doses only rare events of single chromosome/chromatid loss can be observed. Single lagging chromosomes/chromatids can give rise to $\mathrm{MN}$ in daughter cells, while disrupted or multipolar and c-mitoses can give rise to daughter cells with one or more main nuclei, with or without one or more MN (see [19]). For our colchicine treatments we selected doses capable of inducing MN starting from those employed for fish chromosome analysis, capable of inducing c-mitotic arrest.

Cyprinus carpio was chosen both because it is very common in the low course of Italian rivers and for its ecological peculiarities which make it a potentially good bioindicator. Moreover, it has been proposed as a suitable organism for genotoxicity and mutagenicity biomonitoring $[20,21]$ of polluted sites.

\section{Materials and methods}

Experimental animals, obtained by artificial reproduction in Aquaculture Laboratory, were 1-year-old carps, their weight ranging between 17 and $49 \mathrm{~g}$. During all the phases of the experiment fish were maintained in facilities consisting of 1001 aquariums fed with well water (open system) at a temperature of $16-17^{\circ} \mathrm{C}$.

Blood samples were obtained by cardiac puncture on anaesthetised fish (2-phenoxyethanol, $3 \mathrm{ppm}$ ) with heparinised syringes. This technique was chosen because repeated blood samplings can be performed on the same individuals without suffering for the animals; in fact in this and in previous experiments [8] no lethality which could be ascribed to cardiac puncture was recorded.

\subsection{X-ray irradiation}

Groups of 5-8 carps received a single irradiation of $\mathrm{X}$-rays at the doses: $0.1,0.5$ and $2 \mathrm{~Gy}(250 \mathrm{kV}, 6 \mathrm{~mA}$, $3 \mathrm{~mm} \mathrm{Al}, 0.75 \mathrm{~Gy} / \mathrm{min}$ ). These doses were chosen on the basis of reference literature [12] and of our preliminary experiments for dose selection in carps. During irradiation carps were laid with very little water, in order to avoid quenching activity of water.

Six blood samples were taken from the same individuals $3,7,14,21,35$ and 50 days after irradiation.

\subsection{Single injection colchicine treatment}

Groups of six anaesthetised fish received a single i.p. injection $(0.01 \mathrm{ml} / \mathrm{g}$ b.w. $)$ of sterile physiologic solutions of colchicine (Sigma) (CAS registry no. 64-86-8) at the concentrations: $1.6 \times 10^{-2}, 8 \times 10^{-2}$, 


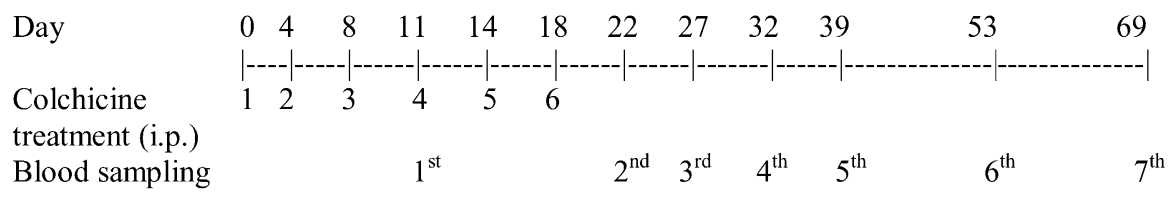

Fig. 1. Experimental schedule of colchicine repeated treatments.

0.4 and $2 \mathrm{mg} / \mathrm{kg}$ b.w. Control fish were injected with physiologic solution.

Repeated blood samplings (six) were performed on the same individuals $3,7,14,21,35$ and 50 days following treatment.

The choice of dose range was made on the basis both of literature data, where colchicine was used for c-metaphase chromosome preparations in different fish target tissues [10,15-17] and of our results obtained from a preliminary experiment for a rough evaluation of colchicine doses compatible with fish survival. The concentrations 200 and $20 \mathrm{mg} / \mathrm{kg} \mathrm{b.w}$. of colchicine killed the animals within 2 days whereas with $2 \mathrm{mg} / \mathrm{kg}$ b.w. $2 / 4$ fish died in 2 weeks.

\subsection{Repeated injection colchicine treatment}

Groups of eighth anaesthetised fish received six repeated i.p. injection of sterile colchicine (Sigma) solution at the concentrations: $1.6 \times 10^{-2}, 8 \times 10^{-2}$ and $0.4 \mathrm{mg} / \mathrm{kg}$ b.w. Control fish were injected with physiological solution. Injections were performed every 3-4 days covering a period of 18 days. Seven blood samples were collected at different times from the beginning of the treatment, the first one performed at the time of the fourth injection, so as to obtain an information about a possible c-mitotic effect, in the case of fish lethality. The following samples were collected at different time intervals, covering a period of 50 days, according to other sampling protocols (see Fig. 1).

\subsection{Slides preparation and $M N$ analysis}

Blood smears, fixed in absolute methanol for $10 \mathrm{~min}$, were Feulgen stained $(1 \mathrm{~h}$ in Schiff reagent after acid hydrolysis $15 \mathrm{~min}, 60^{\circ} \mathrm{C}$, in $\left.\mathrm{HCl} 1 \mathrm{~N}\right)$. This staining method was chosen for its DNA specificity. Ten thousand erythrocytes per animal, with 5-8 individuals per point, were analysed at the light microscope for MN frequency. Only nucleated erythrocytes with intact cellular and nuclear membrane were scored; rounded particles not larger than $1 / 5$ of the main nucleus and without any connection with it, were accepted as MN (for scoring criteria see also [8,22]). No nuclear anomalies - even if observed - have been recorded, such as lobed, blebbed or notched nuclei reported by Ayllon and Garcia-Vasquez [14], because of their ambiguous origin as a mutagenic event.

Mean MN frequencies, expressed as number of MN per 10,000 erythrocytes, were calculated for each group. Statistical evaluation was performed using the $\chi^{2}$-test with Yate's correction, where pooled data from different sampling times of each dose were compared with the control ones. In addition, unpaired $t$-test with Welch correction was applied for the comparison of data from single experimental points.

\section{Results}

\subsection{X-rays irradiation}

Irradiation with $\mathrm{X}$-rays in the tested dose range (0.1-2 Gy) resulted in a evident dose-response effect; pooled data of different sampling times from each dose showed significant differences from unirradiated fish samples at all the doses (Table 1). In addition the increase of $\mathrm{MN}$ frequencies reached peak values 21 days after the treatment: the induced $\mathrm{MN}$ frequencies at this sampling time were significantly higher than control value at the dose $0.5 \mathrm{~Gy}(P=0.013$, see Table 1$)$.

At the sampling times which follow the peak values decreasing MN frequencies were observed in all experimental doses, reaching control values at the last sampling time.

\subsection{Single-injection colchicine treatment}

No significant induction of $\mathrm{MN}$ is observed on pooled data of the different sampling times in the 
Table 1

Mean MN frequencies (on 10,000 cells, \pm S.E.) detected in carp erythrocytes at different sampling times after treatment with three doses of X-rays ${ }^{\mathrm{a}}$

\begin{tabular}{llllr}
\hline Sampling day after treatment & \multicolumn{3}{l}{ X-ray dose $(\mathrm{Gy})$} \\
\cline { 2 - 5 } & $0(n=5)$ & $0.1^{\mathrm{b}, *}$ & $0.5^{\mathrm{b}, * *}$ & $2^{\mathrm{b}, * *}$ \\
\hline 3 & $0.2 \pm 0.2$ & $0.17 \pm 0.17(n=6)$ & $0.87 \pm 0.35$ & $0.87 \pm 0.35$ \\
7 & $0.4 \pm 0.24$ & $0.86 \pm 0.4(n=7)$ & $1.5 \pm 0.43(n=6)$ & $1.25 \pm 0.52$ \\
14 & $0.2 \pm 0.2$ & $0.67 \pm 0.42(n=6)$ & $1.71 \pm 0.68(n=7)$ & $2.75 \pm 1.5$ \\
21 & $0.2 \pm 0.2$ & $0.87 \pm 0.35$ & $2^{\mathrm{c}, *} \pm 0.53$ & $3.87 \pm 1.87$ \\
35 & $0.6 \pm 0.24$ & $0.37 \pm 0.18$ & $0.86 \pm 0.4(n=7)$ & $2.12 \pm 0.81$ \\
50 & $0.2 \pm 0.2$ & $1 \pm 0.45$ & $0.43 \pm 0.2(n=7)$ & $1 \pm 0.38$ \\
\hline
\end{tabular}

${ }^{a}$ Eight fishes per point were examined if not differently indicated.

${ }^{\mathrm{b}}$ Statistical significance: $\chi^{2}$-test with Yate's correction from control values.

${ }^{\mathrm{c}}$ Statistical significance: unpaired $t$-test with Welch correction from control values.

** $P<0.01$

${ }^{*} P<0.05$.

Table 2

Mean MN frequencies (on 10,000 cells, \pm S.E.) detected in carp erythrocytes at different sampling times after a single treatment with different doses colchicine ${ }^{\mathrm{a}}$

\begin{tabular}{llllll}
\hline Sampling day after treatment & \multicolumn{4}{l}{ Colchicine dose (mg/kg b.w.) } \\
\cline { 2 - 6 } & 0 & $1.6 \times 10^{-2}(n=5)$ & $8 \times 10^{-2}$ & 0.4 & $2^{\mathrm{b}, *}$ \\
\hline 3 & 0 & $0.8 \pm 0.37$ & $0.167 \pm 0.167$ & $1.0 \pm 0.36$ & $1 \pm 0.0(n=2)$ \\
7 & 0 & 0 & $0.67 \pm 0.33$ & $0.167 \pm 0.167$ & \\
14 & $0.167 \pm 0.167$ & 0 & 0 & $0.167 \pm 0.167$ & \\
21 & $0.2 \pm 0.2(n=5)$ & $0.4 \pm 0.24$ & $0.67 \pm 0.33$ & 0 & \\
35 & 0 & $0.2 \pm 0.2$ & 0 & $0.167 \pm 0.167$ & \\
50 & 0 & $0.2 \pm 0.2$ & 0 & 0 & \\
\hline
\end{tabular}

${ }^{a}$ Six fishes per point were examined if not differently indicated.

${ }^{\mathrm{b}}$ Statistical significance: $\chi^{2}$-test with Yate's correction from control values.

${ }^{*} P<0.01$.

Table 3

Mean MN frequencies (on 10,000 cells, \pm S.E.) detected in carp erythrocytes at different sampling times after repeated i.p. treatments with different doses of colchicine ${ }^{\mathrm{a}}$

\begin{tabular}{lllll}
\hline $\begin{array}{l}\text { Sampling time (day after } \\
\text { the 1st i.p. injection) }\end{array}$ & \multicolumn{4}{l}{ Colchicine dose $(\mathrm{mg} / \mathrm{kg}$ b.w.) } \\
\cline { 2 - 5 } & 0 & $1.6 \times 10^{-2}$ & $8 \times 10^{-2}$ & $0.4^{\mathrm{b}, *}$ \\
\hline 1st (11) & $0.125 \pm 0.125$ & $0.25 \pm 0.16$ & $0.5 \pm 0.19$ & $3 \pm 2(n=3)$ \\
2nd (22) & $0.125 \pm 0.125$ & 0 & $0.125 \pm 0.125$ & - \\
3rd (27) & 0 & 0 & $0.125 \pm 0.125$ & - \\
4th (32) & $0.28 \pm 0.18(n=7)$ & $0.125 \pm 0.125$ & 0 & - \\
5th (39) & 0 & $0.17 \pm 0.17(n=6)$ & $0.25 \pm 0.16$ & - \\
6th (53) & $0.25 \pm 0.16$ & 0 & $0.33 \pm 0.33(n=3)$ & - \\
7th (69) & $0.125 \pm 0.125$ & 0 & 0 & \\
\hline
\end{tabular}

${ }^{a}$ Eight fishes per point were examined if not differently indicated.

${ }^{\mathrm{b}}$ Statistical significance: $\chi^{2}$-test with Yate's correction from control values.

${ }^{*} P<0.01$. 
tested concentrations, apart from the concentration of $2 \mathrm{mg} / \mathrm{kg}$ b.w. ( $P=0.0045$, see Table 2$)$ at the first sampling time (3 days). This is the highest level of $\mathrm{MN}$ induction found at the same sampling time in this experiment, which was observed both in the fish sample of the concentration $0.4 \mathrm{mg} / \mathrm{kg} \mathrm{b.w}$. and in the two surviving fishes of the $2 \mathrm{mg} / \mathrm{kg}$ b.w. colchicine concentration, the main effect of which was the induction of lethality (4/6 specimens).

\subsection{Repeated injection colchicine treatment}

At the highest colchicine concentration $(0.4 \mathrm{mg} / \mathrm{kg}$ b.w.) five carps out of eight died after the 3rd colchicine i.p. treatment, therefore the first blood sampling have been performed on three fishes only. Yet, even these three fishes died soon after the 4th administration, indicating a high toxicity of this colchicine concentration, possibly because of a cumulative effect of the previous administrations. Apart from this experimental point, where a significant MN increase was found ( $P<0.0001$, see Table 3 ), no other significant difference is detectable (Table 3 ).

\section{Discussion and conclusions}

From a comparison among control data present in the literature on erythrocytes from different species of fish a wide spectrum of variability is evident, which covers a range of values from less than $0.1 \mathrm{MN}$ up to more than $10 \mathrm{MN}$ per 1000 erythrocytes (see Table 4). Our data $(0.02 / 1000$ cells $)$ can be placed at the lowest extreme of the range. In this scale, a variation of two to three orders of magnitude is evident, which might reflect intrinsic differences among the biological systems in mutagenic damage expression (e.g. DNA repair efficiency) or differences in the yield of MN erythrocyte production after $\mathrm{MN}$ formation. As far as the frequency of spontaneous $\mathrm{MN}$, estimates reported by different authors in Oncorhynchus mykiss are similar (see Table 4), while a consistent discordance of data is

Table 4

Examples of spontaneous MN frequencies in fish erythrocytes (on 1000 cells) recorded by different authors in different species (data from the literature)

\begin{tabular}{|c|c|c|c|}
\hline $\begin{array}{l}\text { Range of MN frequency } \\
\text { (on } 1000 \text { erythrocytes) }\end{array}$ & Species & MN frequency (on 1000 cells) & References \\
\hline \multirow[t]{8}{*}{$13-1.0$} & Cyprinus carpio & 6.2 & [18] \\
\hline & Esox lucius & 5.3 & {$[30,31]$} \\
\hline & Carassius auratus gibelio & $13 ; 10 ; 5.2$ & {$[32]$} \\
\hline & Salmo trutta fario & $2.8-0.75$ & {$[22]$} \\
\hline & Cyprinus carpio & 1.2 & {$[21]$} \\
\hline & Oncorhychus mykiss & 1 & [12] \\
\hline & Rutilus rutilus & $13-3$ & [33] \\
\hline & Perca fluviatilis & $10-9$ & [33] \\
\hline \multirow[t]{11}{*}{$0.9-0.09$} & Phoxinus phoxinus & $0.3-0.7$ & [14] \\
\hline & Poecilia latipinna & $0-0.4$ & [14] \\
\hline & Cheirodon interruptus interruptus & $0.0-1.0$ & {$[25]$} \\
\hline & Heteropneustes fossilis & 0.25 & [11] \\
\hline & Genyonemus lineatus & 0.8 & {$[4]$} \\
\hline & Paralabrax clathratus & 0.8 & {$[4]$} \\
\hline & Ictalurus nebulosus & 0.14 & [34] \\
\hline & Umbra limi & 0.14 & [34] \\
\hline & Oncorhynchus mykiss & 0.33 & [7] \\
\hline & Oncorhynchus mykiss & 0.12 & [35] \\
\hline & Carassius auratus & $0.18 ; 0.0$ & [36] \\
\hline \multirow[t]{4}{*}{$0.09-0.00$} & Umbra pygmaea & 0.0 & [9] \\
\hline & Barbus plebeius & 0.05 & {$[8]$} \\
\hline & Cyprinus carpio & 0.03 & {$[21]$} \\
\hline & Cyprinus carpio & 0.02 & Present data \\
\hline
\end{tabular}


evident in the carp (see Table 4). The MN frequencies from our control data appear to be the lowest among those reported on the different species of teleost fish tested up to now; among carps they are very close to the lowest extreme value of the control MN frequency range observed by Nepomuceno et al. [21] (Table 4).

\subsection{X-ray experiments}

$\mathrm{X}$-ray treatments show significant increases of MN frequencies with the increasing doses, up to the peak observed for all the doses at 21 days after exposure (Table 1). At this sampling time the $\mathrm{MN}$ frequencies induced by the X-ray doses of $0.1,1$ and $2 \mathrm{~Gy}$ correspond to a 2.9-, 6.67- and 12.9-fold increase over the control values, respectively. On the other hand, Knowles [23] did not find a significant increase of MN frequency in Pleuronectes platessa erythrocytes after a chronic $\gamma$-irradiation at the total dose of 4.7 Gy.

The time course of $\mathrm{MN}$ rise of our experiments is in good agreement with what reported by Schultz et al. [12] on erythrocytes of rainbow trout (Oncorhynchus mykiss). They exposed groups of fishes to $4 \mathrm{~Gy}$ of $\mathrm{X}$-rays and separately analysed immature and mature erythrocytes by flow cytometric and semi-automatic image analyses up to 58 days after exposure. The MN increase observed in the whole erythrocyte population, which is of about 7-fold above the control value, reached a peak value around the third week after treatment, followed by a plateau up to the last sampling time: interestingly when the distinction among immature and mature erythrocytes was performed they also found a similar time course of $\mathrm{MN}$ induction and decrease as in our experiment, but only in immature erythrocytes, while in mature erythrocytes the MN increase was detectable at the latest time.

Similar results on the time for reaching the peak value of $\mathrm{MN}$ induction after treatment were also obtained by Nepomuceno et al. [21] in erythrocytes of Cyprinus carpio treated with different concentrations and exposure times of metallic mercury, who found a maximum MN frequency after the third-fourth week from the beginning of exposure.

A dose-dependent and time-dependent response to $\mathrm{MN}$ inducing agents has been ascertained by other authors [11,24,25]. As a speculative observation on the time course of MN induction, according data taken together seem to suggest a rather long cell cycle of the stem cells of this tissue, (see below). Indeed, very little is known on the dynamics of hematopoietic tissue in fish, yet the average turnover time for erythrocyte was estimated to be of 150 days [26].

\subsection{Colchicine experiments}

Apart from single experimental points, i.e. the highest tested concentrations from both single- and repeated-colchicine administrations where the MN values correspond to about a 7- and 23-fold increase over their control values, a clear effect of the spindle poison is not detectable.

Positive results on MN increase, detected $24 \mathrm{~h}$ after colchicine treatment of Phoxinus phoxinus and Poecilia latipinna are reported by Ayllon and Garcia-Vasquez [14]. Their tested concentration $(10 \mathrm{mg} / \mathrm{kg})$ is 5 - and 25 -fold higher than our highest ones $(2 \mathrm{mg} / \mathrm{kg}$ and $0.4 \mathrm{mg} / \mathrm{kg}$ in acute and chronic administration, respectively), which significantly increased the MN frequencies, yet killed the animals. Their results differ from ours also because of two differences in the experimental design: (1) the sampling time $(24 \mathrm{~h}$ versus $72 \mathrm{~h})$ and (2) the cell population examined (cephalic kidney erythrocytes versus circulating erythrocytes). The early time of sacrifice, probably, would not allow the detection of any MN increase in circulating erythrocytes, while its appearance in erythrocytes from the cephalic kidney, the haematopoietic tissue in fish where immature or early erythrocytes are present, is reported. In our experiments only lower concentrations allowed the analysis on $\mathrm{MN}$ induction and a later appearance of $\mathrm{MN}$ increase could be detectable in the mature erythrocytes of circulating blood at the 3rd day.

The early appearance of an increase of MN frequencies, that in our colchicine experiments appears at the first sampling time, differently from the later times observed in the X-ray treatments, is not in contrast with what can be expected from a treatment with a spindle poison, the effect of which should be detectable immediately after the end of the damaged mitosis, where chromosome loss is induced; actually, a rough estimation of the cell cycle length of stem cells of fish erythrocytes [16] gives an indication of about 3 days, which corresponds to the time of our MN increase (Tables 2 and 3). 
On the other hand, this slight effect on $\mathrm{MN}$ induction is detected only at a colchicine concentration which is five times lower than that used by Krishnaja and Rege [10] for c-metaphase chromosome preparations in a different species. Preliminary experiments previously carried out in our laboratory for the choice of colchicine concentrations to be tested for $\mathrm{MN}$ induction were performed in the range between 200 and $20 \mathrm{mg} / \mathrm{kg} \mathrm{b.w}$. and led to death of all animals within 1-2 days after a single i.p. administration. This range covered the concentrations employed by several authors for c-metaphase analysis of chromosome preparations from different fish tissues [10,15-18]. The highest concentration of the present work compatible with fish survival in single i.p. treatments $(0.4 \mathrm{mg} / \mathrm{kg}$ b.w. $)$ is similar to those employed for $\mathrm{MN}$ induction in mouse bone marrow (i.p. treatments) by spindle poisons [27,28].

Our negative results from the first protocol performed with single i.p. treatments were interpreted as being due to a too short time of exposure to the spindle poison of the target cells (mitotic cells). Actually, a spindle poison is expected to exert its effect during the mitotic phase of the cell cycle, which is a narrow "target" compared to that of a clastogen like X-rays, i.e. the whole cell cycle length. Moreover, if the cell cycle duration for stem cells of circulating erythrocytes is similar to that of gill cells, which was estimated by Alink et al. [16] to be of at least 3 days, then it would be likely that the absence of $\mathrm{MN}$ increase after a single treatment could be due to a too short time treatment. It was therefore possible that only a few cells were hit by the agent and a chronic treatment could have been more suitable. The aim of the second protocol of administration was therefore to "enlarge" the target, i.e. the number of cells sensitive to the treatment, which was a compromise between an ideal chronic exposure and repetitive injections, monitoring the animals for the $\mathrm{MN}$ incidence every 3-4 days.

The absence of effect observed in the repeated administration experiment, at the second sampling time, (performed 4 days after the last i.p. administration), in spite of the previous repeated injections, is of difficult interpretation. At this sampling time an increase or maintenance of a previously increased frequency of $\mathrm{MN}$ was expected, at least for the highest tested concentration. These results altogether indicate a general lack of sensitivity, for chromosome loss induction, to these low colchicine concentrations.

Our negative results can be explained by a sensitivity of this biological system confined to extremely high concentrations of colchicine, at which toxic/lethal effects prevail upon the cytogenetic effects such as chromatid/chromosome loss and MN formation; such high concentrations in theory could induce the widest spectrum of mitotic disturbances, from single chromosome misdistribution (leading to $\mathrm{MN}$ formation) to c-mitotic effects (leading to polyploidy), yet obscured by fish lethality. In this hypothesis, the $\mathrm{MN}$ increase of the highest doses of our results represents the lightest mitotic damage induced: therefore the range of colchicine concentrations between 0.4 and $2 \mathrm{mg} / \mathrm{kg}$ b.w., should be the only one at which the mutagenic effect can be evidenced as $\mathrm{MN}$ induction in Cyprinus carpio circulating erythrocytes, above which it is not possible to investigate, in vivo. This hypothesis seems to fit also with the results reported by Ayllon and Garcia-Vasquez [14].

The MN test in circulating erythrocytes of Cyprinus carpio responds positively to clastogenic effects, tested through X-rays, similarly to the rainbow trout [12]; the data are also in agreement with other findings concerning $\mathrm{MN}$ induction by other substances tested in other teleost fish, yet showing the lowest control values among those reported in the literature. On the other hand caution must be taken with the pure mitoclastic agent colchicine, since it shows an extreme level of toxicity, at least after i.p. administration; actually, this route of administration was preferred since water exposure of Brachydanio rerio to this compound was performed by Roche et al. [29], who observed low toxicity levels explained by a low absorption from the water. Indeed, our colchicine data do not exclude the sensitivity of the system to other compounds exherting a mitoclastic effect, for the positive results obtained at the highest concentrations.

\section{Acknowledgements}

The authors are extremely grateful to Prof. M. Rizzoni for critical reading of the manuscript and helpful discussion. 


\section{References}

[1] A. Klingerman, Fishes as a biological detector of the effects of genotoxic agents, in: J.A. Heddle (Ed.), Mutagenicity: New Horizons in Genetic Toxicology, Academic Press, New York, 1982, pp. 435-453.

[2] M.L. Landolt, R.M. Kocan, Fish cell cytogenetics: a measure of the genotoxic effects of environmental pollutants, in: J.O. Nriagu (Ed.), Aquatic Toxicology, Wiley, New York, 1983, pp. 335-352.

[3] K. Al Sabti, C.D. Metcalfe, Fish micronuclei for assessing genotoxicity in water, Mutation Res. 343 (1995) 121-135.

[4] J.E. Hose, J.N. Cross, S.G. Smith, D. Diehl, Elevated circulating erythrocyte micronuclei in fish from contaminated sites off southern California, Mar. Environ. Res. 22 (1987) 167-176.

[5] W.D. Gronlund, S.L. Chan, B.B. McCain, R.C. Clark, M.S. Myers, J.E. Stein, D.W. Brown, J.T. Landahl, M.M. Krahn, U. Varanasi, Multidisciplinary assessment of pollution at three sites in Long Island Sound, Estuaries 14 (3) (1991) 299-305.

[6] J.B. Hughes, A.T. Hebert, Erythrocyte micronuclei in Winter Flounder (Pseudopleuronectes americanus): results of field surveys during 1980-1988 from Virginia to Nova Scotia and in Long Island Sound, Arch. Environ. Contam. Toxicol. 20 (1991) 474-479.

[7] S. De Flora, L. Viganò, F. D'Agostini, A. Camoirano, M. Bagnasco, C. Bennicelli, F. Melodia, A. Arillo, Multiple genotoxicity biomarkers in fish exposed in situ to polluted river water, Mutation Res. 319 (1993) 167-177.

[8] S. Minissi, E. Ciccotti, M. Rizzoni, Micronucleus test in erythrocytes of Barbus plebeius (teleostei, pisces) from two natural environments: a bioassay for the in situ detection of mutagens in freshwater, Mutation Res. 367 (1996) 245-251.

[9] R.N. Hooftman, W.K. de Raat, Induction of nuclear anomalies (micronuclei) in the peripheral blood erythrocytes of the eastern mudminnow Umbra pygmaea by ethyl methanesulphonate, Mutation Res. 104 (1982) 147-152.

[10] A.P. Krishnaja, M.S. Rege, Induction of chromosomal aberrations in fish Bolephthalmus dussumieri after exposure in vivo to mitomycin $\mathrm{C}$ and heavy metals mercury, selenium and chromium, Mutation Res. 102 (1982) 71-82.

[11] R.K. Das, N.K. Nanda, Induction of micronuclei in peripheral erythrocytes of fish Heteropneustes fossilis by mitomicin C and paper mill effluent, Mutation Res. 175 (1986) 67-71.

[12] N. Schultz, L. Norrgren, J. Grawe, A. Johannison, O. Medhage, Micronucleus frequency in circulating erythrocytes from rainbow trout (Oncorhynchus mykiss) subjected to radiation, an image analysis and flow cytometric study, Comp. Biochem. Physiol. 105C (1993) 207-211.

[13] I.B. Bahari, F.M. Noor, N.M. Daud, Micronucleated erythrocytes as an assay to assess actions by physical and chemical genotoxic agents in Clarias gariepinus, Mutation Res. 313 (1994) 1-5.

[14] F. Ayllon, E. Garcia-Vasquez, Induction of micronuclei and other nuclear abnormalities in European minnow Phoxinus phoxinus and mollie Poecilia latipinna: an assessment of the fish micronucleus test, Mutation Res. 467 (2000) 177-186.
[15] A. Klingerman, Induction of sister-chromatid exchanges in the central mudminnow following in vivo exposure to mutagenic agents, Mutation Res. 64 (1979) 205-217.

[16] G.M. Alink, E.M.H. Frederix-Wolters, M.A. van der Gaag, J.F.J. van de Kerkhoff, C.L.M. Poels, Induction of sister-chromatid exchanges in fish exposed to Rhine water, Mutation Res. 78 (1980) 369-374.

[17] R.N. Hooftman, The induction of chromosome aberration in Notobranchius rachowi (pisces: Cyprinodontidae) after treatment with ethyl methanesulphonate or benzo(a)pyrene, Mutation Res. 91 (1981) 347-352.

[18] K. Al Sabti, Clastogenic effect of five carcinogenic-mutagenic chemicals on the cells of the common carp Cyprinus carpio L, Comp. Biochem. Physiol. 85 (1986) 5-9.

[19] G. Deysson, Antimitotic substances, Int. Rev. Cytol. 24 (1968) 99-148.

[20] R. Pandragi, M. Petras, S. Ralph, M. Vrzoc, Alkaline single cell gel (Comet) assay and genotoxicity monitoring using bullheads and carp, Environ. Mol. Mutagen. 26 (1995) 345-356

[21] J.C. Nepomuceno, I. Ferrari, M.A. Spanò, A.J. Centeno, Detection of micronuclei in peripheral erythrocytes of Cyprinus carpio exposed to metallic mercury, Environ. Mol. Mutagen. 30 (1997) 293-297.

[22] K. Belpaeme, K. Delbeke, L. Zhu, M. Kirsh-Volders, Cytogenetic studies of PCB77 on brown trout (Salmo trutta fario) using the micronucleus test and the alkaline comet assay, Mutagenesis 11 (1996) 485-492.

[23] J.F. Knowles, Long term irradiation of a marine fish, the plaice Pleuronectes platessa: an assessment on size and composition of the testes and of possible genotoxic changes in peripheral erythrocytes, Int. J. Radiat. Biol. 75 (1999) 773-782.

[24] R.N. Hooftman, G.J. Vink, Cytogenetic effects on the eastern mudminnow, Umbra pygmaea, exposed to ethyl methanesulfonate, benzo[a]pyrene, and river water, Ecotoxicol. Environ. Safety 5 (1981) 261-269.

[25] M.A. Campana, A.M. Panzeri, V.J. Moreno, F.N. Dulout, Genotoxic evaluation of the pyrethroid lambda-cyhalothrin using the micronucleus test in erythrocytes of the fish Cheirodon interruptus interruptus, Mutation Res. 438 (1999) 155-161.

[26] R. Fange, Fish blood cells, in: W.S. Hoar, D.J. Randall, A.P. Farrel (Eds.), Fish Physiology, Vol. XII, Part B, Academic Press, San Diego, 1992, pp. 2-46.

[27] F. Vigagni, H. Norppa, Comparison of separated erythrocyte preparations and manual smears of bone marrow in showing micronucleus induction by clastogens and aneuploidogens in mouse, Mutagenesis 10 (1995) 365-369.

[28] G. Schriever-Schwemmer, U. Kliesch, I.D. Adler, Extruded micronuclei induced by colchicine or acrylamide contain mostly lagging chromosomes identified in paintbrush smears by minor and major mouse DNA probes, Mutagenesis 12 (1998) 201-207.

[29] H. Roche, G. Boge, G. Peres, Acute and chronic toxicities of colchicine in Brachidanio rerio, Bull. Environ. Contam. Toxicol. 52 (1994) 69-73. 
[30] K. Al Sabti, Micronuclei induction in pike (Esox lucius) in Swedish lakes contaminated with radiocesium, Cytobios 70 (1992) 27-32.

[31] K. Al Sabti, Monitoring the genotoxicity of the radiocontaminants in Swedish lakes by fish micronuclei, Cytobios 70 (1992) 101-106.

[32] K. Al Sabti, M. Franko, B. Adrijanic, S. Knez, P. Stegnar, Chromium induced micronuclei in fish, J. Appl. Toxicol. 14 (1994) 333-336.

[33] A. Tuvikene, S. Huuskonen, K. Koponen, O. Ritola, U. Maurer, P. Lindstrom-Seppa, Oil shale processing as a source of aquatic pollution: monitoring of the biological effects in caged and feral freshwater fish, Environ. Health. Perspect. 107 (1999) 745-752.
[34] C.D. Metcalfe, Induction of micronuclei and nuclear abnormalities in the erythrocytes of mudminnows (Umbra limi) and brown bullheads (Ictalorus nebulosus), Bull. Environ. Contam. Toxicol. 40 (1988) 489-495.

[35] A. Castano, G. Carbonell, M. Carballo, C. Fernandez, S. Boleas, J.V. Tarazona, Sublethal effects of intraperitoneal cadmium injections on rainbow trout (Oncorhynchus mykiss), Ecotoxicol. Environ. Saf. 41 (1998) 2935.

[36] T. Ueda, M. Hayashi, Y. Obtsuka, T. Nakamura, J. Kobayashi, T. Sofuni, A preliminary study of the micronucleus test using fish erythropoietic and embrionic cells, Water Sci. Technol. 25 (11) (1992) 235240 . 